\title{
Psychological causes of cyber-aggression in orphaned adolescents
}

\author{
Svetlana Antipina ${ }^{1,{ }^{*}}$, Elena Bakhvalova $^{1}$ and Anastasia Miklyaeva ${ }^{1}$ \\ ${ }^{1}$ Herzen State Pedagogical University of Russia, Institute of Psychology, 191186, Saint Petersburg, \\ Russia
}

\begin{abstract}
The article presents the results of a study aimed at analyzing and comparing the psychological causes of cyber-aggression in adolescents living in a parent family and an orphanage. The empirical research is based K.S. Runions's theory cyber-aggression [1]. K.S. Runions describes cyberaggression of adolescents through their motivational goals and ability to behavioral self-control. Data collection was carried out using a Typological Questionnaire of cyber-aggression, a projective drawing "Man in the rain", and a Questionnaire for assessing the involvement of adolescents in Internet communication. The study involved 223 adolescents aged 10-17 (22\% from orphanages. Participation in the study was voluntary, and everyone had the informed consent. The results show that adolescents raised in orphanages are more clearly prone to cyber-aggression, especially in the case of impulsive-aversive and controlled-appetitive forms. Adolescents, generally, are more willing to display appetitive forms of cyber-aggression; they are able to show aggression against other users for the sake of reward and entertainment. The results of the study showed that the tendency to cyberaggression correlates with sociability and hostility of the world, and in adolescents from parental families with the need for communication, demonstrativeness and aggression in adolescents left without parental care.
\end{abstract}

\section{Introduction}

Recent technical progress and development of society have contributed to the introduction and widespread dissemination of information and telecommunication technologies. Adolescents perceive the global network as a habitat, as an important aspect of their lives. According to the results of Internet research conducted by TNS Russia, about $76 \%$ of adolescents spend at least three hours a day on the Internet, and every seventh teenager aged 12-17 spends almost a third part of their lives in virtual reality (about eight hours a day) [2]. Online communication attracts adolescents with its simplicity and convenience, but, in addition to benefits and pleasure, it also carries various threats.

Among the threats emerging in cyber-space, it is necessary first of all to pay attention to the phenomenon of cyber-aggression. Cyber-aggression is the deliberate harm of other Internet users in order to assert their personal worth [3; 4]. In modern society, the phenomenon of cyber-aggression is gaining wide popularity among adolescents and youth.

\footnotetext{
*Corresponding author: a.miklyaeva@gmail.com
} 
Cyber-aggression manifests in various forms of online behavior, such as sending derogatory messages, public insults, spreading deliberately false information and incriminating data, posting provocative messages, damaging personal photos, etc. According to the World Health Organization (WHO) report, in the 11-year-old age group, Russia ranks first in cyberaggression, ahead of Greenland, Lithuania, Bulgaria, Ukraine and Latvia, and third in the prevalence of cyberbullying among 13- and 15-year-olds [5]. Cyber-aggression differs significantly from "face-to-face" aggression, this difference is determined by the peculiarities of the Internet space. By using the Internet, cyber attackers can intimidate their potential victims around the clock. Modern Internet technologies allow an aggressor to keep his/her personal data private. The unpredictability and unexpectedness of the aggressor's actions deprive the victim of the opportunity to protect himself/herself from aggressor's negative actions. The distance of cyber-aggression makes the behavior of the aggressor uncontrollable and allows him/her to plan further actions, regardless of the possible reactions of the victim. Anonymity and a sense of impunity serve as triggers for antisocial behavior on social media. According to K.S. Runions [1], adolescent cyber-aggression can be described in terms of their motivational goals (appetitive or aversive cyber-aggression) and behavioral self-control ability (impulsive or controlled cyber-aggression). This model suggests four forms of cyberaggression in adolescence: impulsive-aversive, controlled-aversive, impulsive-appetitive, and controlled-appetitive [6].

Speaking about the psychological prerequisites of cyber-aggression in adolescence, we can refer to empirical studies showing that cyber-aggression is associated with high levels of aggression [7], low levels of affective empathy, emotional intelligence [8] and self-control [9], as well as high levels of stress and depression [10]. Adolescents who are prone to cyberaggression show withdrawal, low self-esteem, a lack of communication and understanding with both parents and peers [11], and a higher level of social anxiety. The social status of a teenager, according to a number of researchers, also has an impact. Popular teens are more prone to cyber-aggressive behavior. Adolescents who receive less support from friends and family, or those who feel insecure, such as in school, who have socialization difficulties, are at greater risk of cyber-victimization.

Russian researchers note that online communication is one of the main forms of online activity for adolescents who are brought up in orphanages [12]. In Russia, at all times, orphans were a special, vulnerable part of the child population. Today, due to the development of virtual information and communication technologies and universal access to social networks and various sites, this group of children is exposed to additional danger from the dynamically developing virtual space. A number of Internet organizations and destructive groups actively involve children from socially unprotected segments of the population into their ranks, and some of them specialize in this contingent. Currently, there are no psychological studies of the cyber-aggression of adolescents who are brought up in orphanages and other residential institutions. At the same time, there is enough information about those psychological characteristics of orphans, which are usually considered as psychological prerequisites for cyber-aggression. Researchers identify a special type of personality in adolescents deprived of parental care. These adolescents demonstrate a weak development of self-control, a predominance of reactive behavior, orientation towards external control, a tendency to overly emotional reaction, resentment, high levels of aggression, suspicion and anxiety [13], as well as a tendency to depression [14]. At the same time, their emotional intelligence and self-control, as a rule, are formed at a lower level, compared to adolescents from parental families [15]. Adolescents-orphans are more at risk of problematic Internet use, since the Internet often becomes a source of compensation for the specific needs of orphans for emotional relaxation, self-affirmation, the formation of attachments, etc. [16]. However, they usually do not have sufficient communication skills and choose non-constructive methods of communication associated with manipulation and 
pressure, which often manifest themselves in aggressive actions [17]. In summary, it can be assumed that these psychological characteristics of adolescents deprived of parental care contribute to the development of cyber-aggression in online communication, but this hypothesis requires empirical testing.

\section{The present study}

This research was focused on the analyzing the personal correlates of cyber-aggression of adolescents left without parental care, in comparison with coevals living in families. The first hypothesis suggested that the forms of cyber-aggression between these samples of adolescents differ. We suggested orphan teenagers are more aggressive during online communication. According to the second hypothesis, the personal background of cyberaggression among adolescents in these samples is different. Finally, according to the third hypothesis, those adolescents who live in parental families have more diverse personal backgrounds for cyber-aggression than their coevals who are raised in orphanages.

The research involved 223 adolescents from Saint Petersburg and the Leningrad region aged 10-17 $(\mathrm{M}=12.9, \mathrm{SD}=1.6,51.1 \%$ male), including 48 adolescents who were raised in orphanages $(\mathrm{M}=14.4, \mathrm{SD}=1.5,37.5 \%$ male), and 175 adolescents living in parent families $(\mathrm{M}=12.5, \mathrm{SD}=1.4,54.9 \%$ male). The research was conducted in schools after classes. The participation in the study was voluntary; everyone had the informed consent of a parent (for adolescents from parental families) or the Director of an orphanage (for children in orphanages). Materials for the study were presented to participants in the "pencil-paper" format, filling out the questionnaires took about 40 minutes.

\section{Method}

The tendency to cyber-aggression and its leading motives were assessed with the questionnaire "Typology of cyber-aggression" [6]. The questionnaire considers two dimensions of cyber-aggression (aversive/appetitive and controlled/impulsive) and allows you to assess various motives for cyber-aggression, such as impulsive-appetitive, impulsiveaversive, controlled-appetitive and controlled-aversive cyber-aggression, as well as the general trend towards cyber-aggression. The author's version of the questionnaire includes 29 items that require assessment according to a 5-point scale (from 1 - "almost never" to 5 "constantly"). For this study the questionnaire was interpreted into Russian.

The assessment of teenagers' involvement in Internet communication was carried out by the questionnaire, which included four questions: 1) How many hours a day are you online? ("less than one hour"; "1-3 hours"; "4-8 hours"; "8 hours or more"); 2) How many hours do you spend for online communicating in social networks, chats, forums? ("less than one hour"; "1-3 hours"; "4-8 hours"; "8 hours or more"); 3) How often do you demonstrate aggression in online communicating? ("never"; "rarely"; "sometimes"; "often"; "constantly"); 4) How often do you receive aggression from other Internet users? ("never"; "rarely"; "sometimes"; "often"; "constantly").

Personal prerequisites of cyber-aggression were studied using the projective drawing "Man in the rain" (E.V. Romanova, T.I. Sytko) [18]. The projective drawing was evaluated according to the parameters "coping resources with difficulties", " self-assessment", "aggressiveness", "anxiety", "demonstrativeness", " the world hostility ", "sociability" and "need for communication" using a 5-point scale. The method of double-blind examination was used for verification of ratings. It was followed by comparison of ratings using correlation analysis (Spearman's correlation coefficient, $r_{s}$ ). Spearman's coefficient was also used in the processing of the main data set to identify the relationship between the motives 
of cyber-aggression and personal characteristics. The data analysis also included comparison of adolescents' samples (adolescents who were raised in orphanages, $A O$, and adolescents who lived in parent families, $A F$ ) by the Mann-Whitney test $(Z)$ and the Fisher test $\left(\phi^{*}\right)$ :. These calculations were computed by IBM SPSS Statistics.

\section{Results}

According to the results, the differences in the indicator of propensity to cyber-aggression as well as the indicators of the individual motives for cyber-aggression were not too significant. The difference between the samples was found in the indicators of impulsive-aversive $\left(\varphi^{*}=-\right.$ 2.5 at $\mathrm{p}<0.05)$ and controlled-appetitive $\left(\varphi^{*}=-2.40\right.$ at $\left.\mathrm{p}<0.05\right)$ cyber-aggression, which were higher in the sample of adolescents raised in orphanages. In general adolescents are mainly characterized by proactive forms of cyber-aggression ( $\mathrm{AF}-30.01 \pm 10.6 ; \mathrm{AO}-32.17 \pm 6.8)$, in comparison with the aversive forms ( $\mathrm{AF}-28.02 \pm 9.3$; $\mathrm{AO}-30.83 \pm 6.9)$ (Table 1). In a sample of adolescents living in families, significant differences were found in the manifestation of impulsive-aversive cyber-aggression between boys and girls. Boys are more likely to show cyber-aggression as a response to provocations from other users $(Z=-2.13$, $\mathrm{p}=0.05$ )

Table 1. Motives of cyber-aggression in adolescents raised in orphanages and parental families.

\begin{tabular}{|c|c|c|}
\hline Motives of cyber- aggression & $\mathbf{A O}(\mathbf{M} \pm \mathbf{S})$ & $\mathbf{A F}(\mathbf{M} \pm \mathbf{S})$ \\
\hline Impulsive-Aversive (IA) & $37.23 \pm 7.97$ & $33.65 \pm 11.25$ \\
\hline Controlled-Aversive (CA) & $17.58 \pm 3.74$ & $16.29 \pm 4.89$ \\
\hline Controlled-Appetitive (CAp) & $20.00 \pm 4.12$ & $18.12 \pm 6.83$ \\
\hline Impulsive- Appetitive (IAp) & $15.63 \pm 3.55$ & $14.89 \pm 5.29$ \\
\hline Total indicator & $90.43 \pm 16.84$ & $82.94 \pm 26.41$ \\
\hline
\end{tabular}

Analyzing table 1 we can assume that the overall propensity for aggression in Internet communication on the part of adolescents left without parental care is significantly higher $\left(\varphi^{*}=-2.4\right.$ at $\left.p<0.05\right)$, and in general it has more thoughtful and controlled character. Thus, the first hypothesis of our research can be considered partially confirmed.

In addition, adolescents raising in orphanages, according to their own estimates, spend about the same amount of time online as their coevals from parental families. There was no difference in the self-assessment of the experience of cyber-aggression on the samples. Adolescents of both groups report that they rarely show aggression towards other users and usually do not become victims of cyber-aggression (Table 2).. The self-assessment questionnaires showed significant differences between girls and boys. Girls who are raised in an orphanage spend more time on social networks, chats and forums than boys $(Z=2.49$ with $\mathrm{p}=0.05)$. Also, girls who live in their parents' families are more likely to receive aggression from other users than boys $(Z=1.99$ with $p=0.05)$

Table 2. Average values, standard deviations, and correlations of the total indicator of cyberaggression, online-time, frequency of aggression during communication on the network, and aggression from other users. Note: ${ }^{*}-\mathrm{p}=0.05 ; *{ }^{*} \mathrm{p}=0.01$.

\begin{tabular}{|c|c|c|c|c|c|c|c|}
\hline Indicators & M & SD & $\mathbf{2}$ & $\mathbf{3}$ & $\mathbf{4}$ & $\mathbf{5}$ \\
\hline \multicolumn{6}{|c|}{ Adolescents raising in orphanages } \\
\hline 1. Total indicator of cyber-aggression & 90.44 & 16.84 & -0.22 & -0.27 & $-0.35^{*}$ & -0.05 \\
\hline 2. Daily time spent online & 2.25 & 0.81 & 1.0 & $0.65^{* *}$ & $0.39^{*}$ & $0.33^{*}$ \\
\hline $\begin{array}{c}\text { 3. Daily time spent in social networks, } \\
\text { chats, forums }\end{array}$ & 1.85 & 0.77 & & 1.00 & $0.46^{* *}$ & 0.23 \\
\hline
\end{tabular}




\begin{tabular}{|c|c|c|c|c|c|c|}
\hline $\begin{array}{c}\text { 4. The manifestation of aggression } \\
\text { during online communication to the } \\
\text { other users }\end{array}$ & 2.02 & 0.84 & & & 1.00 & $0.51^{* *}$ \\
\hline $\begin{array}{c}\text { 5. Frequency of aggression from other } \\
\text { users }\end{array}$ & 2.15 & 0.83 & & & & 1.00 \\
\hline \multicolumn{6}{|c|}{ Adolescents from parental families } & \\
\hline 1. Total indicator of cyber-aggression & 82.94 & 26.41 & $-0.29^{* *}$ & $-0.33^{* *}$ & $-0.26^{* *}$ & $-0.24^{*}$ \\
\hline 2. Daily time spent online & 2.3 & 0.83 & 1.00 & $0.59^{* *}$ & $0.50^{* *}$ & $0.31^{* *}$ \\
\hline $\begin{array}{c}\text { 3. Daily time spent in social networks, } \\
\text { chats, forums }\end{array}$ & 1.69 & 0.76 & & 1.00 & $0.41^{* *}$ & $0.25^{* *}$ \\
\hline $\begin{array}{c}\text { 4. The manifestation of aggression to } \\
\text { the other users during online } \\
\text { communication }\end{array}$ & 1.86 & 0.75 & & & 1.00 & $0.52^{* *}$ \\
\hline $\begin{array}{c}\text { 5. Frequency of aggression from other } \\
\text { users }\end{array}$ & 2.01 & 0.95 & & & & 1.00 \\
\hline
\end{tabular}

Table 2 shows that a negative relationship was found between the total indicator of cyberaggression, time spent online and in social networks, and self-assessment of the manifestation and receipt of aggression in the network. There was no significant difference between the samples.

A comparative analysis of the indicators of personal prerequisites for cyber-aggression showed differences between the samples only in the parameters of "aggressiveness" and "need to communicate". These indicators are higher in the sample of adolescents raised in orphanages (Table 3).

Table 3. Personal prerequisites for cyber-aggression in the samples of adolescents raised in orphanages and adolescents from parent families. Note: ${ }^{*}-\mathrm{p}=0.05$.

\begin{tabular}{|c|c|c|c|}
\hline Personal characteristics & $\mathbf{A O}(\mathbf{M} \pm \mathbf{S})$ & $\mathbf{A F}(\mathbf{M} \pm \mathbf{S})$ & $\mathbf{Z}$ \\
\hline Resources of coping with difficulties & $2.38 \pm 1.16$ & $2.29 \pm 1.24$ & - \\
\hline Self-assessment & $2.75 \pm 0.67$ & $2.9 \pm 0.65$ & - \\
\hline Aggressiveness & $3.27 \pm 0.84$ & $2.03 \pm 0.90$ & $7.13^{*}$ \\
\hline Anxiety & $3.56 \pm 0.58$ & $3.41 \pm 0.98$ & - \\
\hline Demonstrativeness & $2.69 \pm 1.26$ & $2.78 \pm 1.55$ & - \\
\hline Hostility of the world & $2.85 \pm 0.87$ & $2.83 \pm 1.16$ & - \\
\hline Sociability & $2.69 \pm 0.99$ & $2.44 \pm 1.02$ & - \\
\hline Need for communication & $3.13 \pm 0.87$ & $2.53 \pm 0.87$ & $4.07^{*}$ \\
\hline
\end{tabular}

Note: ${ }^{*}-\mathrm{p} \leq 0.001$

The results of correlation analysis show that the propensity to cyber-aggression in general and its individual forms particularly in different groups of adolescents are related to different personal characteristics. In the sample of adolescents from parental families, no relationship was found between the total indicator of cyber-aggression, its motives, self-esteem and hostility of the world, while in the group of adolescent orphans, no relationship was found between the propensity to cyber-aggression, its forms and personal indicators: "resources for coping with difficulties", "anxiety" and "need to communicate". In a sample of adolescents from parent families, all the identified correlations have a positive coefficient. The relationship between the indicators "hostility of the world", "sociability" and forms of cyberaggression are specific in the sample of adolescents left without parental care. These correlations are mainly negative. "Sociability" in a group of adolescents from parental families is related to initiative forms of cyber-aggression. There are no universal correlations between cyber-aggression and personal characteristics for both samples (Table 4). 
Table 4. Correlation analysis results (statistically significant correlation, $\mathrm{p} \leq 0.05$ ).

\begin{tabular}{|c|c|c|c|c|c|}
\hline \multirow{2}{*}{ Indicators } & \multicolumn{4}{|c|}{ Motives of cyber-aggression } & \multirow{2}{*}{ Total indicator } \\
\hline & IA & CA & CAp & IAp & \\
\hline \multicolumn{6}{|c|}{ Adolescents raising in orphanages } \\
\hline Self-assessment & - & - & 0.24 & - & 0.22 \\
\hline Aggressiveness & 0.31 & - & - & - & 0.21 \\
\hline Demonstrativeness & 0.21 & - & - & - & - \\
\hline Hostility of the world & - & -0.30 & - & -0.27 & -0.24 \\
\hline Sociability & -0.39 & - & -0.33 & -0.29 & -0.36 \\
\hline \multicolumn{6}{|c|}{ Adolescents from parental families } \\
\hline Resources of coping with difficulties & 0.17 & 0.19 & 0.22 & 0.16 & 0.20 \\
\hline Aggressiveness & 0.21 & 0.24 & 0.17 & 0.16 & 0.21 \\
\hline Anxiety & - & - & - & 0.17 & 0.15 \\
\hline Demonstrativeness & 0.26 & 0.28 & 0.32 & 0.22 & 0.28 \\
\hline Sociability & - & - & 0.17 & 0.22 & 0.17 \\
\hline Need for communication & 0.28 & 0.23 & 0.33 & 0.41 & 0.32 \\
\hline
\end{tabular}

Table 4 data suggest that cyber-aggression of adolescents living in parental families is related to personal problems increasingly, such as demonstrativeness and aggression. Adolescents in this sample want to communicate (the need for communication and cyberaggression demonstrate the highest correlation coefficient, a positive correlation between forms of cyber-aggression and sociability). It seems that cyber-aggression for this group of adolescents is one of the forms of communication, a way of establishing contacts. In turn, among adolescents raised in orphanages, the highest correlations were found between the motives of cyber-aggression and sociability. But orphaned adolescents cannot communicate and do not feel the need to do so. They protect themselves in the process of communication. Thus our hypothesis that the personal background of adolescents' cyber-aggression from different samples differs is confirmed. According to the third hypothesis, we can state a greater variety of personal prerequisites for cyber-aggression, which is specific to adolescents from parental families.

\section{Discussion}

The results of our research indicate the relevance of studying the features of online communication and, in particular, cyber-aggression in adolescents raised in orphanages. In spite of the low means of self-assessment of their online aggression experience, adolescents living in orphanages are significantly more likely to show cyber-aggression. Orphaned adolescents do not see any danger from communicating online, and they underestimate the threats coming from cyberspace. Because of the lack of communicative experience, orphans tend to view cyber-aggression as normative online behavior in contrast to their coevals. They are less aware of the rules of behavior and ethical norms for online communication [19]. Perhaps adolescents who are raised in orphanages use cyber-aggression as a way to reduce communication, so they protect themselves from "unnecessary communication". It is probably the diversity of factors that determines the complexity of the problem of cyberaggression in adolescents who are raised in orphanages. Thus, the first hypothesis of our study was confirmed.

The research also confirmed the hypothesis that the personal background of cyberaggression in adolescents from parental families and adolescents raised in orphanages will differ. The confirmation of this hypothesis is based on the difference in the main characteristics of the personality of adolescents deprived of parental care and their coevals. According to the results, impulsive-aversive forms of online aggression are directly related 
to the level of aggression and demonstrativeness of children in orphanages, and controlledappetitive forms are associated with self-esteem, which is due to the higher level of aggression characteristic of children in orphanages [20], as well as a tendency to anger and destructive behaviors. Orphaned adolescents are constantly evaluated by the staff of the institution (perhaps more often it is a negative evaluating), and it leads to denial, indifference and negative attitude towards others. These adolescents realize their need for communication by means of communication with coevals who live with them in the institution, or with former pupils. The living conditions of orphaned adolescents and their social status contribute to the formation of poor connections outside the orphanage [21].

According to the third hypothesis of our research, we have found a low variety of personal prerequisites for cyber-aggression in adolescents raised in orphanages (compared with their coevals). The results of our research show that the most significant correlates of cyberaggression in adolescents deprived of parental care are "hostility of the world" and "sociability". We can assume that this fact is determined by the peculiarities of the formation of the adolescent's personality and behavior. Perhaps main cause of cyber-aggression in orphaned adolescents is the lack of communication skills and those personal features that are called "the personality of an orphanage child".

\section{Conclusion}

Thus, the results show that adolescents (regardless of their place of residence) face aggressive communication in the Network. $69 \%$ of our respondents note the presence of aggression against them from other Internet users, which indicates a fairly high level of aggression in the online space. The direct link between the time spent online and the forms of cyberaggression highlights the danger of the phenomenon of cyber-aggression. The propensity to cyber-aggression in orphaned adolescents is higher, in comparison with their peers from parental families. The causes of cyber-aggression in adolescence are different these samples. Further research in the field of online communications and cyber-aggression among adolescents raised in orphanages can become the basis for solving one of the most important problem for modern society - reducing the level of aggressiveness of the Internet users and improving the security of online communication. The results of our research could contribute to the development of effective programs of psychological and pedagogical support for the cybersocialization of orphaned adolescents.

\section{Acknowledgements}

The research was supported by the Ministry of Education of the Russian Federation as part of a state task (project No. FSZN-2020-0027).

\section{References}

1. K.C. Runions, Journal of Adolescence 42, 751-771 (2013) DOI: 10.1007/s10964-0139936-2

2. S.A. Moskvichev, Problemy protivodeistviya prestupnosti v sovremennykh usloviyakh, 132-139 (2018)

3. G. Gini, N.A. Card, T. Pozzoli, Aggressive behavior 44(2), 185-198 (2017) DOI: 10.1002/ab.21742

4. M.F. Wright, Cyberpsychology behavior and social networking 20(6), 355-361 (2017) DOI: 10.1089 /cyber.2016.0693 
5. G.U. Soldatova, E.N. L'vova, I.D. Permyakova, Tsifrovoe obshchestvo kak kul'turnoistoricheskii kontekst razvitiya cheloveka, 380-385 (2018)

6. K.C. Runions, M. Bak, T. Shaw, Aggressive behavior 43, 74-84 (2016)

7. E.I. Pogorelova, I.V. Ar'kova, A.C. Golubovskaya, Severo-Kavkazskii psikhologicheskii vestnik 14(2), 47-53 (2016)

8. C. Yudes, L. Rey, N. Extremera, Voces de la Educacion, 27-44 (2019)

9. A.T. Vazsonyi, H. Machackova, A. Sevcikova, D. Smahel, A. Cerna, European Journal of Developmental Psychology 9, 210-227 (2012)

10. M.F. Wright, Youth a. society 47(6), 789-810 (2015)

11. E.O. Malova, Innovatsionnoe razvitie professional'nogo obrazovaniya 2(26), 107-114 (2020).

12. T.A. Arakantseva, I.A. Bobyleva, O.V. Zavodilkina, Obrazovatel'noe prostranstvo v informatsionnuyu ehpokhu, 502-519 (2019)

13. N.N. Kas'yanova, A.G. Martyukhina, Akademiya professional'nogo obrazovaniya 6, 6973 (2018)

14. M. Mohammadzadeh, H. Awang, H. Kadir Shahar, S. Ismail, Mental Health Journal 54(1), 117-125 (2018)

15. T.I. Shulga, D.D. Savchenko, E.B. Filinkova, International journal of environmental \& science education 11(17), 10493-10504 (2016)

16. A.R. Drozdikova-Zaripova, A.R. Shakurova, Vestnik nauchnogo tsentra bezopasnosti zhiznedeyatel'nosti 13(3), 23-31 (2012)

17. E.V. Bakhvalova, Vektor nauki Tol'yattinskogo gosudarstvennogo universiteta 3(34), 51-57 (2018) DOI: 10.18323/2221-5662-2018-3-51-57

18. E.V. Romanova, T.I. Syt'ko, Proektivnye graficheskie metodiki (Piter, Sankt-Peterburg, 1997)

19. I.N. Bondareva, Sovremennye problemy nauki i obrazovaniya 4 (2019)

20. T.A. Popova, L.A. Kanaeva, Fundamental'nye issledovaniya 5(2), 398-401 (2014)

21. A.B. Kholmogorova, T.V. Avakyan, E.N. Klimenkova, D.A. Malyukova, Konsul'tativnaya psikhologiya i psikhoterapiya 23(4), 102-129 (2015) 